\title{
Como era ardiloso o meu francês: Charles-Marie de la Condamine e a Amazônia das Luzes
}

\author{
How cunning was my little Frenchman: Charles-Marie \\ de la Condamine and the eighteenth-century Amazon
}

Neil Safier ${ }^{*}$

\section{Resumo}

Este artigo discute as ferramentas bibliográficas e etnográficas utilizadas por Charles-Marie de la Condamine (17011774) ao representar o rio Amazonas ao público europeu em meados do século XVIII. Partindo de uma análise das suas descrições de populações indígenas e das fontes que La Condamine aproveitou ao longo de sua viagem rio abaixo, destacam-se as estratégias narrativas que lhe possibilitaram escrever um texto repleto de observações supostamente de primeira mão. $\mathrm{O}$ artigo também analisa algumas reações contemporâneas à Relation abrégée d'un voyage fait dans l'intérieur de l'Amérique méridionale (1745), publicadas na Europa e na América do Sul, sobretudo reações à maneira pela qual o texto relatava as características culturais das populações ameríndias e o mito milenar de mulheres guerreiras morando separadas de homens, que se dizia habitavam a região desde o início do século XVI, senão antes.

Palavras-chave: Amazônia; etnografia; exploração.

\section{Abstract}

This paper explores the bibliographical and ethnographic tools used by CharlesMarie de La Condamine (1701-1774) to represent the Amazon River to the European reading public in the mid-eighteenth century. By carefully analyzing La Condamine's descriptions of native populations and the sources upon which he relied as he descended the river, the author emphasizes the narrative strategies he employed to portray his observations as first-person eyewitness accounts. The article goes on to examine contemporary reactions to La Condamine's Relation abrégée d'un voyage fait dans l'intérieur de l'Amérique méridionale (1745), especially the manner in which the text recounted the cultural characteristics of Amerindian populations and the persistent myth of female warriors living apart from men who were thought to populate the region from early in the sixteenth century, if not earlier.

Keywords: Amazon; ethnography; exploration.

\footnotetext{
* Dept. of History, British Columbia University. 1873 East Mall, Room 1297 - Vancouver, BC V6T 1Z1 - Canada. neil.safier@ubc.ca.
} 
Numa quarta-feira, 28 de abril de 1745, o renomado acadêmico francês Charles-Marie de la Condamine apresentou, a uma sessão aberta da mais estimada instituição científica da sua época, o relato de uma viagem através da América do Sul. Naquele dia, na Academia de Ciências de Paris - sociedade erudita da qual era membro - , ele escolheu cuidadosamente uma forma narrativa para apresentar as suas variadas observações sobre a Região Amazônica, entretendo o seu público ao descrever a viagem rio abaixo com descrições de primeira mão, ao invés de produzir um relato exclusivamente histórico. Em vez de dividir o texto em capítulos separados, La Condamine apresentou o seu discurso como uma relation de testemunha ocular, preferindo assim uma forma de narração utilizada pelos exploradores e missionários franceses do início do século XVII, ao relatar os estranhos encontros com tribos iroquesas e algonquinas nas paisagens geladas da Nouvelle France. Sem divisões explícitas entre os capítulos, a Relation abrégée d'un voyage fait dans l'intérieur de l'Amérique méridionale (1745) era um texto que fluía de maneira tão suave quanto o rio que descrevia, sem nenhuma demarcação sistemática entre o relato mais ou menos cronológico da viagem e as discussões sobre geografia, história natural e ritos e costumes indígenas da região. Medidas astronômicas se encontravam no texto junto a relatos míticos de florestas nevoentas, "encantados" palácios dourados e guerreiras ferozes e nuas. As descrições coloridas da flora e da fauna amazônicas presentes na Relation abrégée foram intercaladas com anotações de latitude e longitude, um modelo que prefigurava uma nova fórmula capaz de atrair um público amplo ao mesmo tempo em que se conformava às expectativas rígidas de uma memória acadêmica. A unidade narrativa do texto proporcionava, assim, aos seus leitores um relato ininterrupto da expedição que La Condamine empreendera por toda a extensão do continente sul-americano, das alturas andinas na América espanhola às terras baixas da Amazônia portuguesa, e assim por diante até o Atlântico. Uma resenha do evento, publicada alguns meses mais tarde numa das revistas literárias mais celebradas da França, o Mercure de France, diz que La Condamine "entretinha" a assembleia ao contar a sua descida pelo "fleuve du $\mathrm{Ma}$ ragnon ou des Amazones", e que incluía comentários sobre plantas e animais da região, costumes, crenças e línguas indígenas, os mitos e lendas que diziam respeito à raça de mulheres guerreiras que deram nome ao rio, e a informação geográfica que se encontrava inscrita no "preciso" mapa que ele trouxera na volta à França. ${ }^{1}$ Essa imagem da América do Sul tropical foi fixada no imaginário europeu graças a um francês que se representou como um intrépido voyageur-philosophe. Suas estratégias discursivas serviam para revelar o rio 
Amazonas segundo as normas empíricas das Luzes e, ao mesmo tempo, aproveitavam um formato que não ofenderia as pessoas que preferiam o Robinson Crusoe de Defoe aos Principia Mathematica de Newton. ${ }^{2}$

Dois dias após essa assembleia pública, La Condamine estava de novo à frente da Academia das Ciências, desta vez com o propósito de apresentar os resultados completos a um público mais reduzido, dentro dos muros sagrados da Biblioteca do Rei, no Palácio do Louvre. Nas seis semanas seguintes, em nove sessões da Academia parisiense, La Condamine proferiu uma palestra detalhada sobre os meses que passara descendo o Amazonas de Quito até Caiena. A lista dos presentes incluía personagens estimadas da comunidade científica, tais como o conde de Buffon, o botânico Jussieu, o astrônomo Pierre Bouguer, o naturalista Louis-Jean-Marie Daubenton e o enciclopedista e matemático Jean Le Rond D’Alembert. De fato, La Condamine servia de porta-voz para a comunidade científica de Paris sobre assuntos ligados ao continente sul-americano. Ele lia em voz alta cartas de correspondentes oriundos de Quito e Belém, traduzia e analisava textos em castelhano e patrocinava intercâmbios de sementes e livros entre os membros de uma crescente rede científica na América do Sul e os da comunidade acadêmica europeia.

Os dois eventos aqui descritos - a assembleia pública e a série de séances privadas da Academia parisiense - refletem duas esferas reconhecíveis e superpostas pelas quais o público europeu setecentista conheceu as regiões tropicais da América do Sul, inclusive o Brasil. A popularidade da literatura de viagem e a importância crescente das viagens de exploração dentro das academias científicas facilitaram a emergência de acadêmicos como intelectuais no século XVIII, instruindo um público de leitores curiosos, adeptos de salões e clientes de cafés e casas literárias, os quais absorveram as lendas e estórias que chegaram à Europa. Publicações tais como a Histoire générale des voyages do Abade Prévost (1746-1770) e as Lettres édifiantes et curieuses (1707-1776) enviadas por missionários de além-mar forjaram uma imagem de espaços exóticos não só dentro dos confins das academias científicas, mas também na esfera mais ampla da cultura letrada europeia.

Este artigo propõe-se a mostrar a maneira como La Condamine formulou partes da sua célebre narrativa do rio Amazonas, e a analisar como certos leitores do seu texto responderam a algumas das mais infames - e danosas - asserções feitas sobre os povos indígenas das Américas. Em ambos os casos, à luz de uma análise minuciosa dos textos envolvidos, surgem detalhes reveladores sobre como o texto foi elaborado e construído durante sua viagem ao longo da linha equatorial, através das Américas espanhola e portugue- 
sa, e também como a narração foi lida e interpretada pelos membros eruditos da comunidade científica europeia. Apesar de suas estratégias narrativas parecerem autênticas e sem costura, La Condamine escondeu tanto quanto revelou. Durante a expedição, ele coletou cuidadosamente mapas, manuscritos, correspondência epistolar e histórias missionárias dos indivíduos que encontrou ao longo de seu caminho. Ao mesmo tempo, apoiou-se no conhecimento local e na assistência material de crioulos, ${ }^{3}$ jesuítas, ameríndios e escravos de origem africana. Mas, para dar a coerência e a autoridade de testemunha de primeira mão com as quais ele esperava impressionar os seus superiores na Academia das Ciências, suprimiu várias das fontes que utilizou e escondeu muito da ajuda recebida. Para apresentar o rio Amazonas em meio impresso, La Condamine sublinhou suas observações como testemunha ocular e criticou aqueles textos que poderiam ser vistos como narrativas concorrentes. Tomou emprestadas observações etnográficas de relatos manuscritos, sem citar suas fontes, e se aproveitou da correspondência epistolar de eruditos americanos para organizar suas conclusões geográficas. Enfim, para "compilar" o rio Amazonas para um público europeu, La Condamine recolheu materiais extremamente diversificados e criou a ilusão de que haviam sido coletados por suas próprias observações in situ. Quando reunidos na Relation abrégée, esses recortes deram uma nova imagem da geografia sul-americana para uma das instituições europeias mais eminentes, e constituíram uma versão própria de La Condamine da Amazônia no século das Luzes. Ao examinar os contextos locais nos quais La Condamine conduziu suas investigações e ao depurar os esforços que ele fez para suprimir suas fontes de informações, este artigo busca revelar os sítios sociais e culturais que afetaram o acadêmico sábio e peripatético durante sua viagem através da América do Sul e mesmo depois de seu retorno, mostrando o momento preciso em que a Região Amazônica foi revelada como objeto de estudo - e um cobiçado lugar de exploração - para as ferramentas da ciência ocidental. ${ }^{4}$

Em 1735, La Condamine foi enviado à América do Sul com outros membros da Academia das Ciências para resolver um dos maiores debates científicos do século XVIII: a forma do globo terrestre. A "figura da Terra” era a de um "esferoide prolato" inchado nos polos, como pensava René Descartes, ou achatado nos polos, como predizia Isaac Newton nos seus Principia Mathematica (1687)? Duas expedições sob os auspícios do rei francês foram despachadas para resolver a questão e avaliar a forma da Terra. Um grupo de cientistas 
se reuniu a Pierre-Louis Moreau de Maupertuis e viajou à Lapônia em 1737, enquanto Louis Godin, um membro sênior da Academia, foi com os "geômetras" Charles-Marie de La Condamine e Pierre Bouguer às montanhas de Quito, no então vice-reino espanhol do Peru. Quando a expedição à Lapônia voltou com um resultado confiável mesmo antes de os membros da expedição sul-americana terem concluído suas observações, La Condamine decidiu aumentar sua reputação científica na Europa por meios diferentes e mais ousados. Escolheu um caminho que, segundo ele, ninguém invejaria, descendo o "rio das Amazonas" desde o ponto em que este se torna navegável - Jaén de Bracamoros, hoje no Peru - pelo lado oriental da cordilheira dos Andes, através do continente sul-americano, até a foz do Amazonas no Atlântico. ${ }^{5}$

Uma vez decidido a voltar à Europa pelo rio Amazonas, La Condamine prontamente escreveu a um amigo, o marquês de Valleumbroso, para informá-lo sobre suas intenções. O marquês era Don Josef Pardo de Figueroa y Acuña, um crioulo nascido em Lima, cujo irmão era bispo da Guatemala e cujo sobrinho era vice-rei do México, o marquês de Castel-Fuerte. Valleumbroso aprovou com gosto o itinerário programado pelo acadêmico: "Celebro a determinação da viagem que vossa excelência me informa que pretende empreender pelo rio Marañón," escreveu o marquês. Acontece que Valleumbroso era sobrinho-neto de Cristóbal d'Acuña, autor da crônica da viagem de Pedro de Teixeira pelo rio Amazonas, realizada entre 1637 e 1639. Valleumbroso queria conhecer o estado do conhecimento sobre o rio e sobre a geografia amazônica: "Já terá visto que estranhas são nestes países as ciências matemáticas", lamentou Valleumbroso numa carta a La Condamine, "e o pouco que se pode confiar nos mapas comuns, que pela maior parte se têm formado sobre relatos pouco certos, e por nada exatos". Antes disso, Valleumbroso havia solicitado ao padre Andrés de Zarate, da missão jesuítica de Quito, que compilasse os diários de Pablo Maroni, uma série de comentários sobre a geografia do rio, os quais Zarate mandava ao marquês, em Cuzco. Mas a sua fome não foi satisfeita: "Eu desejava notícias pontuais e modernas do [rio] Marañón”, Valleumbroso continuava na carta, "e [queria] saber do estado presente desse grande rio". Assim, La Condamine se beneficiava dos relatos e observações mais recentes, recolhidos em campo, transcritos numa carta abreviada e enviados ao acadêmico francês um ano e meio antes de empreender a sua própria descida do rio. ${ }^{6}$

Embora seja impossível saber até que ponto La Condamine se apoiava diretamente nas observações de Valleumbroso para formular suas estratégias críticas em relação ao conhecimento prévio sobre o rio e sua geografia, é evi- 
dente que tirou alguns elementos da carta de Valleumbroso e adaptou-os aos seus próprios fins. Por exemplo, La Condamine referiu-se à narrativa de Cristobal d'Acuña como um "relato puramente histórico", repetindo quase com as mesmas palavras a avaliação de Valleumbroso de que pouco se sabia em detalhes sobre o rio antes da visita de Acuña em 1640: "assim, até o padre Acuña publicar o relato da sua viagem, que foi somente histórico, não se sabia com fundamento coisa alguma desse rio". Trocando algumas palavras, La Condamine transformou a frase e aproveitou-se da lógica sintática Valleumbrosiana para insistir em que nada, desde o relato de Acuña, tinha sido escrito: "Não se sabe hoje na Europa nada sobre os países atravessados pelo [rio] Amazonas fora daquilo que se apreendeu há mais de um século por meio do relato do padre d'Acuña" (La Condamine, 1745, p.15). Desta maneira, La Condamine criou as circunstâncias da sua própria entrada na história aproveitando-se de uma estratégia empregada por Valleumbroso mas distorcendo-a. Assim, o francês insinuava que nenhum conhecimento relevante havia sido obtido desde a viagem de Acuña, cem anos antes.

Uma das pessoas que La Condamine implicitamente criticava com essa retórica era o jesuíta boêmio Samuel Fritz, que passou quase quatro décadas na Amazônia ocidental como missionário e jesuíta superior, tendo chegado em 1684. O mapa da bacia amazônica compilado por Fritz circulou em várias versões impressas e manuscritas pela Europa, tornando-se um testemunho gráfico dos mais importantes no que diz respeito ao aumento das atividades missionárias e dos esforços catequéticos de espanhóis e portugueses no início do século XVIII. ${ }^{7}$ Ao descrever as explorações do padre Fritz no Amazonas, o que fez de maneira pejorativa, La Condamine recorreu a termos similares aos utilizados por Valleumbroso. O marquês observou que "como o dito padre fez sua viagem estando doente, não confio muito em suas longitudes e latitudes, pois não estaria em condições de fazer as suas observações com a exatidão necessária". ${ }^{8}$ La Condamine também criticou o jesuíta por estar doente e por faltarem-lhe instrumentos apropriados para chegar a conclusões que pudessem ser verificadas de forma científica, justamente aqueles aspectos da viagem que Valleumbroso sublinhou em sua carta. "Basta ler o seu diário manuscrito", escreveu La Condamine na sua Relation abrégée, "para ver que muitos obstáculos, no local e após o retorno à sua Missão, impediram que fizesse as observações necessárias para fabricar um mapa exato" (La Condamine, 1745, p.14-15).

Valleumbroso também ofereceu instruções explícitas a La Condamine no que diz respeito ao tipo de observações que devia fazer ao longo da via- 
gem, às fontes que devia consultar, e à forma da sua narrativa: "Não duvido que em Quito V. Exa. possa conseguir [mapas], e, com as notícias que V. Exa. possa tirar dos portugueses, [consiga] formar um mapa muito perfeito, no qual V.Exa. mostra os erros que até aqui têm ocorrido nos mapas que se têm feito deste rio e seus contornos". O marquês sugeriu confiança em certos mapas até certo ponto ("até o lugar onde você embarca, pode contar com o mapa do padre Fritz...") e apontou quais relatos deviam ser comparados com observações de primeira mão para compilar uma vista mais ampla do lugar: "[E] assim procure recolher todos os relatos dessas viagens, e se existirem também os mapas, para servir no mapa que formará deste grande rio ... você dará muita luz para uma geografia até agora tão ignorada...". 9

A descrição textual de Valleumbroso ofereceu uma fonte abundante para La Condamine e encaixou-se perfeitamente em suas ambições para a viagem fluvial. O marquês proporcionou a La Condamine um arsenal de argumentos com o qual ele estabelecia a preeminência e a autoridade de suas próprias observações. A despeito do seu interesse em "assegurar-se da realidade" das características do rio, apoiou-se numa carta escrita por um residente de Cuzco que passava a sua vida a procurar informações precisas sobre o caminho seguido por seu bisavô no século anterior. Assim, os conceitos geográficos de La Condamine se originavam tanto da leitura que Valleumbroso fez dos relatos de viagem amazônicos quanto das observações que La Condamine recolheu com seus próprios olhos enquanto desceu o rio.

Porém, a característica que mais distinguia a Relation abrégée dos tratados acadêmicos da época era a exaustiva discussão dos ameríndios, um assunto que, normalmente, ficava um pouco à margem do escopo da Academia, mas que certamente atrairia o entusiasmo de seus membros e de um público mais amplo, com interesses filosóficos. Suas afirmações mordazes a respeito dos povos indígenas sul-americanos, que ele descreve como preguiçosos, de pouca inteligência, glutões e inaptos para o pensamento racional, faziam parte de um vocabulário comum na discussão sobre os ameríndios, compartilhado por muitos autores europeus à época do início de sua viagem, especialmente na medida em que uma visão a respeito dos vários estágios do desenvolvimento humano se tornou predominante entre naturalistas e filósofos europeus, de Montesquieu a Hume. ${ }^{10}$ As observações de La Condamine tiveram um efeito especialmente negativo para o imaginário europeu do ameríndio, uma vez que esse viajante era, no mais das vezes, percebido como um observador confiável aos olhos dos leitores europeus. Por exemplo, La Condamine declarou, sem pestanejar, que "todos ou a maioria dos índios ameri- 
canos são mentirosos", deixando pouca dúvida sobre o quanto ele confiava nos conhecimentos científicos ou geográficos dos índios. Também afirmou que a "insensibilidade" era a base do caráter do índio, deixando ao leitor a decisão sobre se essa insensibilidade deveria ser "honrada com o nome de apatia, ou vilipendiada com o de estupidez". Enquanto isso, tomou "as virtudes que se atribuem a muitas [plantas] pelos nativos do país" como base para sua discussão da utilidade da "multiplicidade e diversidade das árvores e plantas que são encontradas nas margens do Amazonas”. Esses mesmos índios que "levam a vida sem pensar e ... envelhecem sem deixar a infância" eram também responsáveis por abrigos contra a chuva "feitos de folhas de palmeiras entrelaçadas [e] habilmente preparadas" (La Condamine, 1745, cit. nas p.111, 52, 74, 63). Essa disjunção entre, de um lado, vilipendiar o caráter das populações indígenas e, de outro lado, elogiar suas habilidades artísticas e seu conhecimento da flora e da fauna amazônicas, exemplifica a atitude conflitante a respeito da cultura nativa no texto de La Condamine.

Qual era a base dessas afirmações cáusticas? Uma comparação cuidadosa da Relation abrégée de La Condamine com um relato manuscrito que ele consultou no distrito espanhol de Maynas demonstra que outros textos, copiados quase literalmente em seu relato, constituíram a verdadeira fonte de muitas de suas observações. Assim como a carta de Valleumbroso predispôs o acadêmico a certas conclusões geográficas antes mesmo que chegasse a ver o rio com seus próprios olhos, La Condamine absorveu muito do que sabia sobre as culturas nativas amazônicas do que tinha lido, e não do que ele próprio observou in loco.

Um texto no qual, em larga medida, ele se baseou foi a "Descrição da província e das Missões de Maynas no reino de Quito", um relato escrito por Jean Magnin (1701-53) sobre as missões em Maynas e as populações indígenas que habitavam a região. Magnin era um jesuíta do cantão de Friburgo (Suíça), que La Condamine conheceu em Borja (Peru), depois de atravessar o cânion de Manseriche. Aos 24 anos, Magnin chegou a Cartagena (Colômbia), vindo da Europa, e começou uma lenta travessia por rios e montanhas até Quito, onde passaria quase três décadas, até sua morte, com 52 anos. No último período de sua vida de missionário, viveu na paróquia de São Francisco de Borja, onde, por três dias, em 1743, recebeu La Condamine e dividiu com ele seu conhecimento sobre as populações da região. Magnin também lhe forneceu um relato manuscrito de suas observações. ${ }^{11}$

As conclusões de La Condamine a respeito dos habitantes nativos da região de Maynas parecem ter sido retiradas diretamente do relato de Magnin. As 
observações de La Condamine sobre a cultura amazônica incluíram julgamentos mordazes dos costumes dos nativos, seu caráter e sua língua, e o manuscrito de Magnin foi, nesse ponto, crucial, ao fornecer a La Condamine evidências para suas generalizações. Em sua "Descrição de Maynas”, Magnin menciona características "bizarras" da vida cultural ameríndia que se tornariam das mais comentadas na Europa do século XVIII, como o hábito dos povos omáguas de tentar deformar o rosto das crianças no parto. Numa seção do manuscrito de Magnin, o jesuíta escreveu que os omáguas estavam "convencidos de que é belo ter uma face lisa como a lua” (Magnin, 1993, p.95). Ao recontar a história, La Condamine, empregando uma voz ativa, faz parecer que os omáguas lhe haviam contado diretamente sobre essas características de sua cultura:

O nome dos omáguas, na língua do Peru, significa "cabeça chata", assim como o de cambevas, que os portugueses do Pará lhes dão na língua do Brasil; de fato, esses povos têm o costume bizarro de esmagar a testa de suas crianças recémnascidas entre duas tábuas, para os deixar com essa estranha forma e para fazêlos lembrar, segundo dizem, a lua cheia. A língua dos omáguas é tão doce e tão fácil de pronunciar e mesmo de aprender quanto a dos yameos é rude e difícil. (La Condamine, 1745, p.72)

A narração ativa que La Condamine faz de seu encontro correspondia a uma expectativa por testemunhos pessoais dentro da Academia, uma linguagem da experiência que lhe permitia fazer parecer que o relato original fora seu. Essas observações, inicialmente presentes no manuscrito de Magnin e mais tarde transcritas para a Relation abrégée de La Condamine, viajaram em seguida da missão de Borja para as páginas da Encyclopédie. O trajeto entre as florestas da América do Sul e as páginas da Encyclopédie, ao percorrer os sucessivos estágios de tradução - o manuscrito de Magnin foi escrito originalmente em espanhol - transcrição e resumo, eliminou a fonte da observação original. No processo, a dívida de La Condamine para com as observações de Magnin ficou obscurecida e deslocada, ou mesmo de todo anulada.

Além de destacar os que lhe pareciam ser os mais peculiares costumes ameríndios, La Condamine também fez afirmações amplas, execrando-lhes o caráter. Novamente, muitas dessas observações consistiam em materiais retirados do relato manuscrito de Magnin, posteriormente coligidos e reorganizados. Magnin escreveu que o caráter dos índios era similar ao de crianças, e que eles eram "tímidos, medrosos e bêbados preguiçosos infiéis, sem reconhecimento e sem memória”. Após quase vinte anos entre os nativos, Magnin 
estava convencido da preguiça dos ameríndios, de sua falta de inteligência e de sua imoralidade; para ele, eram "selvagens contentes" que viviam inteiramente sem cuidados ou medos:

Eles vivem tão contentes com o que possuem, que não desejam mais nada. Fazem pouco caso do que têm, e não desejam absolutamente o que não têm. Se se lhes dá qualquer coisa, não a recebem com gratidão. Se se lhes recusa algo, dir-lheão na sua cara que é por avareza. Se eles o perdem [um objeto], não ficam desapontados; repreenda-os e eles se põem a rir. Elogie-os e eles rirão mais ainda ... Vivem sem preocupações, dormem sem inquietude e morrem sem medo. Poderíamos dizê-los felizes, se a felicidade consistisse em ser insensível. (Magnin, 1993, p.151)

O vocabulário de Magnin foi empregado por La Condamine em sua própria descrição depreciadora dos costumes indígenas. Porém, o acadêmico apresentou essas observações gerais como se fossem a culminação de seus estudos prolongados da vida nativa. Mesmo admitindo que não seria de todo apropriado confiar num viajante que apenas observou as culturas nativas passando rapidamente por elas, ele ainda alegou: "todos os índios americanos dos vários países que tive a ocasião de visitar em minha viagem me parecem, em larga medida, semelhantes uns aos outros". Em seguida, fez uma crítica às populações nativas que foi regularmente citada por detratores da cultura ameríndia ao longo do século, especialmente por aqueles para quem o continente sul-americano era degradado e a cultura de suas populações indígenas era decadente:

A insensibilidade forma a base [de seu caráter]. Deixo ao leitor a decisão sobre se se deveria honrá-la com o nome de apatia ou aviltá-la com o de estupidez. Ela nasce sem dúvida do pequeno número de suas ideias, que não se estendem além de suas necessidades. Glutões até a voracidade, quando têm com que se satisfazer; sóbrios, quando a necessidade os obriga a tanto, a ponto de a tudo renunciar, sem parecer nada desejar; pusilânimes e poltrões em excesso, a não ser quando embriagados; inimigos do trabalho, indiferentes a toda forma de glória, de honra ou de reconhecimento; unicamente ocupados do objeto que têm à sua frente e sempre determinados por ele; sem inquietação a respeito do futuro; incapazes de previsão e de reflexão; quando nada os incomoda, entregam-se a uma alegria pueril, que manifestam com saltos e gargalhadas imoderadas, sem razão e sem objetivo; passam suas vidas sem pensar e envelhecem sem sair da infância, de que conservam todos os defeitos. (La Condamine, 1745, p.51-53) 
Para resumir seus anos de observações, La Condamine se baseou no espírito, e mesmo nas próprias palavras, das descrições etnográficas prévias de Magnin. Este concluiu que uma das características da felicidade ameríndia era ser "insensível”, e La Condamine afirmou, igualmente, que a "insensibilidade" formava a base do caráter dos indígenas; Magnin escreveu que os ameríndios eram "tão indiferentes, ou melhor, tão estúpidos, que eles veriam alguém agonizar até a morte diante de seus olhos antes de sequer pensar em ajudar", e La Condamine, por sua vez, não conseguia decidir se o caráter dos indígenas deveria ser honrado como "apático" ou vilipendiado como "estúpido". Cada uma das conclusões de La Condamine parece ter sido forjada na oficina etnográfica de Magnin. A proposição filosófica da La Condamine, de que "o homem, abandonado à natureza e privado de educação e da sociedade, difere pouco da besta” (Magnin, 1993, p.124; La Condamine, 1745, p.53.), não está muito longe da descrição que Magnin faz da vida ameríndia.

Particularmente impressionante é como La Condamine costurou, com elegância, as observações do jesuíta em sua própria narrativa. Esses detalhes aparecem na Relation abrégée como se La Condamine houvesse observado pessoalmente essas culturas nativas. Em vez de resumir o relato de Magnin e dar o crédito ao jesuíta por suas observações, ele preparou uma narrativa que flui suavemente, de modo que seus leitores descobririam a Amazônia e seus habitantes como se estivessem descendo o rio com o narrador. A estrutura narrativa formou, portanto, uma parte central da integração estratégica desses materiais e da supressão simultânea das origens ou fontes desse material. Para jogar as luzes da Ilustração sobre a Amazônia, La Condamine recorreu a um processo não só de compilação, edição e narração, mas também de acumulação empírica de observações pessoais.

Tais exemplos mostram claramente que La Condamine se baseou no manuscrito de Magnin e usou as observações do jesuíta como se fossem suas. De acordo com Jacques-François Artur, naturalista e médico em Caiena, La Condamine "revisou e corrigiu" a tradução francesa do manuscrito de Magnin "lauda por lauda" durante sua estada por lá, e tinha, portanto, um conhecimento íntimo do que ele continha, ${ }^{12}$ chegando a dizer que o publicaria quando voltasse à Europa. E, contudo, afora explicar que Magnin lhe havia dado "um mapa que ele fez das missões espanholas de Maynas e uma descrição dos hábitos e costumes das nações vizinhas", o francês não menciona muito Magnin. Além de observar que o manuscrito deste fora traduzido pelo doutor Artur com a sua assistência e que era "merecedor do interesse do público", La 
Condamine não faz nenhuma referência ao texto que revele ser este a verdadeira fonte de muitas de suas observações (La Condamine, 1745, p.58).

Sem nenhuma surpresa, La Condamine encerra sua discussão dos costumes nativos precisamente no momento da narrativa em que ia além do alcance do relato de Magnin sobre Maynas: "Na presente ocasião", escreve La Condamine, "não devo me estender sobre os hábitos e costumes dessas nações e de um tão grande número de outras que encontrei, a não ser que elas possam ter alguma relação com a física ou a história natural" (La Condamine, 1745, p.84). La Condamine opta por excluir qualquer discussão adicional sobre a cultura ameríndia, porque não contava com nenhuma evidência material em que pudesse basear suas afirmações. A presença de Magnin foi excluída não porque seu conhecimento fosse perigoso ou politicamente explosivo, mas porque ele diminuiria a imagem de empirista que La Condamine desejava passar à Academia. La Condamine reivindicaria na prosa o status que desejava como um conquistador somente depois de eliminar qualquer vestígio de seus predecessores jesuítas. Apenas depois de apagar as fontes de suas conclusões etnográficas, ele poderia substituir os jesuítas como a última fonte de verdade empírica da Europa.

Como leitores individuais responderam às considerações depreciativas de La Condamine sobre o caráter da população indígena da Região Amazônica? Em outras palavras, qual a imagem criada por essas descrições na mente dos leitores eruditos da Europa? Sabemos que Buffon, Cornelius de Pauw e Jean-Jacques Rousseau eram todos leitores do relato de La Condamine, mas poucas reações pessoais à Relation abrégée sobreviveram até hoje. Uma longa resposta que ainda existe ao texto de La Condamine é aquela de Isaac de Pinto (1717-1787), um descendente de judeus sefarditas de Portugal que emigraram para a Holanda no século XVII. Ao retornar da América do Sul, La Condamine chegou primeiro ao porto seguro de Amsterdã, num navio holandês, uma vez que não queria correr o risco de viajar numa embarcação com a vela da França durante as hostilidades da Guerra de Sucessão Austríaca. Isaac de Pinto havia recebido La Condamine em sua pequena "sociedade literária", que se reunia regularmente para discutir as notícias mais importantes de fora da capital holandesa, incluindo debates significativos ocorridos na comunidade científica europeia. Foi nessa ocasião que os dois eruditos se encontraram e puderam discutir áreas de preocupação comum.

Mas foi a intensa troca epistolar entre os dois, muitos anos depois, sobre 
a representação da América do Sul e o caráter moral dos nativos, mestiços e crioulos do Novo Mundo que mais entusiasmou Isaac de Pinto. Em suas primeiras cartas, este retratou La Condamine como testemunha profética e confiável, portador de uma luz reveladora, que despejava "alguns raios de [sua] luminescência” em sua íntima comunidade em reuniões regulares em Amsterdã: "Temos a vantagem", escreveu De Pinto, "de ouvir de sua boca detalhes das maravilhas que a natureza em outro hemisfério contém”. Citando a representação poética que Voltaire faz dos acadêmicos como "conquistadores da natureza... [que] levantam seu véu”, proclamou, em prosa elegante, que "Newton teve apóstolos dignos de suas realizações" e "não poderia ter confiado seus interesses a melhores mãos". Isaac de Pinto apresentava La Condamine como iluminando o "vulgar" entre os eruditos da Europa, e usava poesia e prosa para enfatizar o serviço generoso que La Condamine realizara em prol do público cultivado. ${ }^{13}$

Porém, à série inicial de lisonjas seguiram-se caracterizações menos elogiosas, nas cartas posteriores. Junto com várias ideias que "tomaram de assalto a imaginação [de Isaac de Pinto]", uma série de dúvidas começou a atormentar o curioso holandês depois de ler a Relation abrégée. Esses questionamentos, que De Pinto delineou ao longo da troca de cartas, desafiaram La Condamine a aprofundar suas afirmações superficiais sobre a cultura ameríndia. Isaac de Pinto ofereceu uma série de amplas reflexões sobre o eventual impacto da presença europeia no Novo Mundo, observações que desafiavam diretamente as descrições negativas que La Condamine havia feito da cultura nativa:

Sua carta, tão instrutiva quanto divertida, foi assunto de um de nossos encontros. Não podíamos, contudo, entender o que você disse sobre os americanos. Você ressalta que eles jamais provocariam uma revolução no Novo Mundo. Eu gostaria de imaginar, você escreve, que, numa ilha deserta, onde se estabeleceria uma família de homens, os macacos ... poderiam se sublevar e tomar o governo. Mas qual seria então a causa dessa ociosidade, dessa indiferença, desse temperamento preguiçoso e indolente que domina o povo, ou melhor, os autômatos? ${ }^{14}$

A transformação figurativa, feita por La Condamine, dos ameríndios em macacos desviou o interesse de Isaac de Pinto para os predicados físicos e morais dos indígenas, o que, por sua vez, dependia da questão mais ampla sobre a adaptabilidade da natureza humana. Se o que La Condamine dizia estava certo, observou Isaac de Pinto, o ameríndio seria "um tipo de humano 
que difere de nossa espécie mais que qualquer outra espécie do mais diversificado animal difere de [outra de] seu tipo". ${ }^{15}$ E se o clima era o único responsável pela indolência e lassidão do ameríndio, afirmava De Pinto, os crioulos europeus nascidos nas Américas estariam sujeitos à mesma degradação. $\mathrm{O}$ erudito holandês manteve-se cético a respeito das assertivas mais polêmicas de La Condamine sobre a inconstância do caráter dos nativos, e o pressionou, em suas cartas, a elaborar melhor o assunto, especialmente no que queria dizer quando descrevia os ameríndios como um "povo selvagem ... que envelhece sem deixar a infância". ${ }^{16}$

O interesse de Isaac de Pinto na relação entre o clima e as características físicas e morais era fortemente influenciado pelas teorias do abade Jean-Baptiste du Bos, autor das Réflexions critiques sur la poësie et sur la peinture e partidário da corrente que julgava importante a influência do clima no desenvolvimento humano. Isaac de Pinto estava especialmente curioso a respeito de até onde o clima seria unicamente responsável pela preguiça e pela indiferença atribuídas aos ameríndios por La Condamine:

Se esse temperamento é tão universal, sua causa deve ser certamente física, e inerente à natureza do clima; supondo ser esse o caso, tal vício inerente deve ser transmitido aos filhos de europeus nascidos nesse país, cujo temperamento deve, consequentemente, se aproximar cada vez mais daqueles do Novo Mundo. ${ }^{17}$

Como Montesquieu e outros que o precederam, Isaac de Pinto usou a teoria de Du Bos sobre o desenvolvimento estético da sociedade e o importante papel do ar e do clima para a evolução artística de um povo para fundamentar suas posições teóricas. ${ }^{18}$ Quando escreveu que os espanhóis nas Américas relutavam em colocar crioulos em posições de autoridade pública, ele ecoava a afirmação de Du Bos segundo a qual "[a Espanha] sempre seguiu a máxima de nunca confiar um único cargo de importância na América aos crioulos espanhóis, ou àqueles nascidos na América”. ${ }^{19}$ Isaac de Pinto e seu círculo literário parecem ter adquirido interesse particular na figura do crioulo, a quem Pinto definia como "aqueles sobre cujo semblante a natureza deixou impresso que são estrangeiros nesse clima” ${ }^{20}$ Articulando a noção dubosiana de que as características raciais e de temperamento sofriam uma mutação quando grupos eram retirados de seu clima de origem, Isaac de Pinto escreveu que "na Holanda ... os filhos e sobrinhos de espanhóis, portugueses e franceses se 'holandizaram', por assim dizer; eles assumiram a mesma coloração, adquiriram o mesmo temperamento [e] adotaram as mesmas 
disposições". ${ }^{21}$ As crenças de Isaac de Pinto sobre o determinismo do clima o levaram, em última instância, a sugerir a possibilidade de uma resposta política da parte de um povo tão duramente subjugado pela autoridade colonial espanhola. ${ }^{22}$ Ele contemplou um futuro no qual as transformações que ocorriam nas colônias americanas e entre seus habitantes criariam uma nova sociedade e um tecido social renovado, em que espanhóis adquiririam os hábitos e as características dos americanos e vice-versa. Isaac de Pinto previu um ambiente em que novas gerações, numa sociedade mestiça, provocariam uma "Revolução" nas colônias, parafraseando, ao mesmo tempo, a observação anterior de Du Bos, segundo a qual "as cortes em Madri parecem ter percebido isso, uma vez que excluíram os crioulos do serviço público". ${ }^{23}$

Mas foi apenas depois da chegada a Amsterdã de um crioulo hispanoamericano chamado Pedro Vicente Maldonado que Isaac de Pinto pôde produzir críticas robustas e contundentes o bastante para questionar diretamente as afirmações etnográficas de La Condamine. Maldonado, um descendente direto de conquistadores espanhóis, que tinha passado sua formação em Riobamba, em meio às populações indígenas dos Andes, havia percorrido o Amazonas com La Condamine e, ao chegar à capital holandesa, deu a Isaac de Pinto coragem para confrontar o francês com sua mais explícita série de objeções, incluindo acusações de que este teria distorcido suas fontes e interpretado de forma imprecisa os sinais que observara. ${ }^{24}$ Contudo, nem mesmo o testemunho ocular de Maldonado foi suficiente para levar La Condamine a adotar uma visão mais nuançada. Ao contrário, ele respondeu aos novos questionamentos de Isaac de Pinto contestando a autoridade de Maldonado, a quem retratou como um inocente partidário, que não estava qualificado para fazer observações imparciais. Em vez de atacar os princípios universais defendidos por Isaac de Pinto e Maldonado, La Condamine criticou a natureza das fontes que eles tentaram empregar. Fez também alusões explícitas aos escritos de dois dos mais ferrenhos defensores da cultura indígena em língua espanhola - Bartolomeu de las Casas e o inca Garcilaso de la Vega —, numa crítica ampla à etnografia espanhola. Las Casas, de acordo com La Condamine, não tinha uma visão mais favorável das faculdades mentais dos índios que a dele, e Garcilaso havia simplesmente apresentado um quadro demasiado simpático à cultura inca. E, ainda que La Condamine não estivesse disposto a escrever críticas tão explicitamente anti-hispânicas em seus textos impressos, ele pôde desviar a atenção de suas afirmações mais questionáveis usando a forma epistolar, instrumentos bibliográficos e referências a autores do passado. Mesmo com o apoio de leitores eruditos e testemunhas oculares as críticas 
nas cartas de Isaac de Pinto e Maldonado se revelaram, em última instância, insuficientes para reverter a imagem da América do Sul defendida por La Condamine em manuscritos e textos impressos.

Se a representação de La Condamine do Amazonas e de seus habitantes nativos se baseava nas narrativas manuscritas de exploradores que o antecederam e nos relatos jesuíticos para formar na mente europeia a imagem da Amazônia com que atravessou o Atlântico, um processo similar ocorreu quando ele descreveu as mulheres guerreiras que teriam dado o nome ao rio: as amazonas americanas. Quando La Condamine retornou à Europa em 1745, sua defesa da existência das amazonas causou certa preocupação entre seus leitores europeus. Na realidade, 50 anos mais tarde, foi Alexander Von Humboldt quem teve de responder mais explicitamente à defesa que La Condamine fez da existência das amazonas. Em sua Relation historique, Humboldt contou que, após retornar à Europa,

as pessoas em Paris frequentemente me perguntavam se eu compartilhava da opinião [de La Condamine] ou se eu acreditava, como muitos de seus contemporâneos, que ele defendeu a existência de Cougnantainsecouima [mulheres guerreiras] ... apenas para se aproveitar de uma generosa recepção numa sessão pública da Academia, e de sua ansiedade por [ouvir] coisas novas. ${ }^{25}$

Independentemente de La Condamine ter defendido essa posição para cativar uma plateia crédula, seus argumentos a favor da existência das amazonas americanas eram baseados menos em mitos do que na história social: a história mais ampla dos escravos fugidos do Novo Mundo. La Condamine conhecia a história dos escravos fugidos por ter dividido sua jangada de Belém do Pará até Caiena com Louis, um “escravo negro”, original de Caiena, que, com vários outros, havia fugido das crueldades do cativeiro para buscar refúgio em território português. Uma vez que um tratado de 1732 assinado entre Portugal e França bania a pena de morte, por considerá-la desumana, decidiu-se em Belém do Pará que os portugueses devolveriam Louis para Caiena, sob a condição de que este voltasse a seu dono de direito. O pequeno barco de La Condamine garantiu seu retorno seguro de uma prisão portuguesa para os grilhões da servidão francesa.

Para defender a ideia de que já houve amazonas na América, numa clara referência à precária condição de escravos fugidos como Louis, La Condami- 
ne argumenta que o comportamento de mulheres vivendo separadas dos homens não seria mais surpreendente ou mais difícil de imaginar do que "o que acontece todos os dias nas colônias europeias da América":

É bastante comum que escravos maltratados ou descontentes fujam em bandos pela floresta ou, ocasionalmente, sozinhos, quando não encontram com quem se associar, e que aí passem muitos anos e, às vezes, toda sua vida na solidão. (La Condamine, 1745, p.111)

Mesmo tendo La Condamine suprimido o fato de que viajara na companhia de Louis, seu relato sobre os escravos fugidos guardava uma extraordinária semelhança com a condição deste homem. Sem o conhecimento de seus leitores, La Condamine fundiu uma narrativa mitológica da antiguidade clássica com sua experiência in situ de dividir um pequeno barco com um escravo fugido.

Mas não foram apenas escravos fugidos os responsáveis pela defesa que La Condamine fez do mito das amazonas. As condições sociais das mulheres ameríndias também desempenharam um papel na posição do francês, e este baseou seus argumentos numa análise material de sua vida:

Se é que já pôde haver amazonas no mundo, foi na América, onde a vida errante das mulheres que seguem seus maridos para a guerra, e que não são mais felizes em sua vida doméstica, deve ter feito nascer nelas a ideia e lhes fornecido ocasiões frequentes de se livrar do jugo de seus tiranos, procurando estabelecer um ambiente onde pudessem viver com independência e, ao menos, não serem reduzidas à condição de escravas ou burros de carga. (La Condamine, 1745, p.110-111)

Essa aparente consciência das condições materiais da vida doméstica ameríndia é notável, se não por outra razão, porque La Condamine raramente discutia a situação das mulheres em seus relatos. Apesar de ter encontrado mulheres ameríndias regularmente em sua viagem, ele quase sempre suprimiu suas experiências in situ com elas. Aqui, porém, parece descrever a condição delas com uma solidariedade atípica.

No caso das amazonas americanas, La Condamine pintou então um quadro que fundia as amargas realidades da servidão africana e as duras condições da vida doméstica ameríndia. Essa extraordinária aliança conceitual entre escravos maltratados fugidos e mulheres nativas escravizadas mina a imagem de La Condamine como um europeu vivendo numa bolha científica 
figurativa, insensível e impermeável às circunstâncias sociais de seu entorno. Esse exemplo ressalta uma epistemologia forjada no cadinho do mundo atlântico do século XVIII: um sistema tão ligado às condições sociais e materiais da subserviência feminina, à escravidão africana e às interações imperiais que atravessavam fronteiras políticas e geográficas, quanto dependente das observações empíricas obtidas por meio de telescópios e barômetros. O exemplo de Louis nos mostra explicitamente que, mesmo que os europeus tenham levado práticas do empirismo para as Américas no século XVIII, forças ocultas de dentro do continente americano também atuavam sobre esses caminhos do conhecimento e da medição. Com referência às amazonas, esse conhecimento percorreu seu caminho desde uma lenda clássica que atravessou o Atlântico no início do século XVI até um pequeno barco que levava um escravo na costa sul-americana, e das condições de sujeição que La Condamine reconhecia no papel das mulheres indígenas até as prensas impressoras do Velho Regime. Em sua jornada pela América do Sul e de volta à Europa, La Condamine tentou suprimir as fontes de onde retirou suas evidências materiais, sua inspiração moral e intelectual e, ocasionalmente, a satisfação de suas necessidades sexuais.

Ao descrever o surpreendente apoio de La Condamine à ideia de que amazonas americanas haviam existido nas terras baixas da América do Sul, o próprio Humboldt não se colocou em nenhum dos lados da questão, nem na defesa de La Condamine, nem junto a seus críticos parisienses. Não obstante, ao descrever um relato do padre Bartolomeu Gili sobre uma conversa que teve com um habitante indígena da região de Encaramada, ao norte do Rio Amazonas, o qual havia proclamado a existência de um grupo de "mulheres vivendo sozinhas" que fabricavam seus próprios instrumentos de guerra, Humboldt deixou claro que considerava o testemunho do missionário bastante confiável e que este estava em conformidade com tudo o mais que se sabia sobre as guerreiras amazônicas desde o tempo de Orellana. Sua explicação merece uma citação completa:

O que se deve concluir desse relato do velho missionário [Gili]? Não que haja amazonas nos rios de Cuchivero, mas que, em diferentes partes da América, mulheres, cansadas do estado de escravidão em que são mantidas pelos homens, se reuniam, como os negros fugidos, num quilombo; que o desejo de conservar sua independência as transformou em guerreiras; [e] que elas receberam, de qualquer grupo vizinho e amigo, visitas, talvez um pouco menos metodicamente do que afirma a tradição. Teria bastado que essa sociedade de mulheres tivesse ad- 
quirido alguma força em uma das partes da Guiana para que eventos muito simples, que podem ter se repetido em diferentes lugares, tenham sido descritos de maneira uniforme e exagerada. Isso é típico das tradições. E se o levante extraordinário de escravos de que falei anteriormente tivesse tido lugar não perto da costa da Venezuela, mas no meio do continente, um povo crédulo teria visto em cada quilombo de negros marrons a corte do rei Miguel... Os caraíbas da TerraFirme (Venezuela) se comunicavam com essas ilhas e é, sem dúvida, por essa via que as tradições do Marañón e do Orenoco se propagaram para o Norte. Antes da navegação de Orellana, Cristóvão Colombo já acreditava ter visto amazonas nas Antilhas. (Humboldt, 1970, p.487-488)

Aqui, Humboldt faz uma forte defesa do apoio de La Condamine ao mito das amazonas, valendo-se até de alguns dos mesmos argumentos que o próprio La Condamine usara para dar a seus leitores parisienses o material de uma fábula do século XVI. Todos os mesmos elementos estão lá: mulheres em estado de escravidão, "abandonadas" por seus maridos; escravos fugidos em quilombos; uma sede de independência transformando esposas em guerreiras. De fato, é digno de nota que Humboldt se refira à semelhança entre amazonas e escravos fugidos, pois é precisamente esse o argumento que La Condamine empregara para defender a ideia. $\mathrm{O}$ apoio de La Condamine ao mito amazônico devia muito à própria experiência de dividir um pequeno barco com um escravo fugido da Guiana Francesa, o qual havia buscado refúgio no território português atravessando uma fronteira política que separava jurisdições com diferentes leis relativas ao tratamento dos escravos. No caso de $\mathrm{La}$ Condamine, essa experiência de alguém que tivesse atravessado a fronteira foi crucial para determinar a natureza do mito que se perpetuara desde Orellana, e mesmo desde Colombo. No caso de Humboldt, suas pesquisas sobre a natureza das amazonas também foram conduzidas numa região fronteiriça, entre as Guianas, Terra-Firme e o Brasil, no interior úmido que veio a ser chamado Amazônia. ${ }^{26}$

Deve ser dito que nem todos os leitores da Relation abrégée estavam tão certos da veracidade do relato de La Condamine quanto Humboldt. Trinta anos após a viagem do francês, o ouvidor e jurista português Francisco Xavier Ribeiro de Sampaio (1741-1812?) empreendeu uma jornada de reconhecimento territorial de dois anos através da região do rio Negro, passando por muitos dos mesmos lugares que La Condamine descrevera. Leitor atento de 
La Condamine, Sampaio divergiu de muitas de suas conclusões, tentando minar sua autoridade e diminuir o prestígio de seu predecessor: "A estabelecida reputação do sr. de la Condamine poderia iludir aos que, sem acesso a informações mais precisas, lessem seus escritos ... É pena que homem tão ilustre quisesse desilustrar-se dessa forma" ${ }^{27}$ Sampaio, em seguida, questiona uma série de antigas lendas sobre as amazonas que La Condamine defendeu numa seção intitulada "Breve dissertação sobre o nome do rio Amazonas e a existência das mulheres amazonas". Citando uma série de autores canônicos que haviam discutido a existência fabulosa das mulheres guerreiras, incluindo Laet, Raleigh, Coronelli e o próprio La Condamine, Sampaio apresenta citações detalhadas de seus testemunhos, mas, ao fim, se vê impossibilitado de compartilhar tais opiniões: "E se examinarmos esta matéria usando as regras da verdadeira lógica, e uma sólida crítica, devemos assentar que a existência das amazonas da América é uma daquelas preocupações populares, que, achando fundamento no maravilhoso, que o povo ama, assumem vida própria e se propagam com extraordinária facilidade" (Sampaio, 1825, p.29). Em vez de avaliar o mito consultando fontes indígenas, Sampaio se baseou em filósofos do século XVIII para demonstrar a implausibilidade de tal mito:

Que coisa mais difícil [haveria] de se conceber por qualquer entendimento são, que uma república de mulheres, que habitem a zona tórrida, governando[-se] por si, sem admitirem o varão, que [não] em certos dias do ano? Que causas morais podemos imaginar, que sejam tão eficazes para vencer a quase irresistível força do clima? O ânimo é sumamente agitado nos climas cálidos, por tudo o que é relativo à união dos dois sexos: tudo conduz a este objeto, diz um jurisconsulto filósofo. (Sampaio, 1825, p.29)

O feito de Sampaio foi ter combinado o testemunho ocular com a consulta in loco de textos filosóficos, incluindo Do espírito das leis, de Montesquieu. Ele construiu uma crítica coerente do método de La Condamine, não baseada unicamente no empirismo do testemunho ocular, mas envolvendo também seus próprios padrões internos de racionalidade crítica, combinados com um desejo de apoiar as ambições políticas da Coroa portuguesa.

Porém, no final das contas, apesar das várias contestações à confiabilidade e à coerência lógica de suas teorias, foi a imagem que La Condamine criou do rio, dos ancestrais míticos da região e de seus habitantes indígenas que prevaleceu e deleitou um público europeu ansioso por histórias exóticas de "países pouco conhecidos" do mundo. E foi Jean-Jacques Rousseau quem po- 
pularizou a ideia de um "viajante filosófico", à imagem de La Condamine, que teria "viajado para instruir seus compatriotas", discutindo a extraordinária diversidade dos costumes humanos. ${ }^{28}$ Esse retrato de La Condamine como um relator objetivo de informações de primeira mão, coletor de espécimes e um observador científico imparcial, foi o que o próprio La Condamine promoveu junto à Academia quando de seu retorno. Ele usou todos os instrumentos à disposição para justificar sua viagem ao Novo Mundo como o representante de uma nova ordem científica. Seu popular tratado recebeu elogios tanto por sua utilidade para a ciência, como pelos talentos literários de seu autor. A Relation abrégée de La Condamine, mais que qualquer outro relato contemporâneo, conduziu leitores europeus pelo Amazonas do século XVIII, introduzindo a comunidade científica e o público amplo de leitores a um novo mundo, que, nos dois séculos e meio que se seguiram, tornou-se um importante laboratório e uma poderosa metáfora para a riqueza e a diversidade da vida animal e vegetal da Terra. Porém, como este artigo demonstra, o explorador francês, que foi tão intimamente relacionado à história do rio durante esse período, adquiriu sua reputação à custa de muitos outros, desde jesuítas até escravos fugidos: indivíduos que forneceram muito do testemunho ocular com o qual La Condamine pôde construir suas imagens coerentes da Amazônia do século XVIII. Foi esse legado mistificador de observações in loco próprias - e não alheias - que criou, na época do Iluminismo, um retrato tão duradouro da Amazônia, um quadro que conseguiu sobreviver - e, infelizmente, mesmo prosperar - até nossos dias.

(Tradução: Manuel Amaral Bueno)

\section{NOTAS}

1 "SÉANCE publique de l'Académie des Sciences", Mercure de France, Août 1745, p.100.

${ }^{2}$ LA CONDAMINE, Charles-Marie de. Relation abrégée d'un voyage fait dans l'intérieur de l'Amérique méridionale. Depuis la côte de la mer du Sud, jusqu'aux côtes du Brésil é de la Guiane, en descendant la riviere des Amazones; lûe à l'assemblée publique de l'Académie des Sciences, le 28 avril 1745. Paris: Veuve Pissot, 1745 [1746]). No gênero misto dos relatos científicos populares e narrativas de viagem, ver SAFIER, Neil. Unveiling the Amazon to European science and society: the reading and reception of La Condamine's Relation abrégée. Terrae Incognitae, n.33, p.33-47, 2001. Para uma breve biografia de La Condamine em português, ver RAMINELLI, Ronald. Charles La Condamine. In: VAINFAS, Ronaldo (Org.). Dicionário do Brasil Colonial (1500-1808). Rio de Janeiro: Objetiva, 2000. 
${ }^{3}$ A palavra "crioulos" é usada aqui no sentido de filhos de europeus nascidos na América. (N.T.)

${ }^{4}$ Estes temas, e outras discussões encontradas neste artigo, são elaborados de forma mais ampla em SAFIER, Neil. Measuring the New World: Enlightenment science and South America. Chicago: University of Chicago Press, 2008.

${ }^{5}$ Sobre as origens da expedição para Quito, ver LAFUENTE, Antonio; MAZUECOS, Antonio. Los caballeros del punto fijo: ciencia, política y aventura en la expedición geodésica hispanofrancesa al virreinato del Perú en el siglo XVIII. Madrid: CSIC; Serbal, 1987; HOARE, Michael Rand. The quest for the true figure of the Earth: ideas and expeditions in four centuries of geodesy. Aldershot: Ashgate, 2005; LAFUENTE, Antonio; DELGADO, Antonio J. La geometrización de la tierra: observaciones y resultados de la expedición geodésica hispano-francesa al virreinato del Perú, 1735-1744. Madrid: CSIC, 1984; ZÚNIGA, Neptalí. La expedición científica de Francia del siglo XVIII en la Presidencia de Quito. Quito: Municipio de Quito, 1986; LORIDAN, Jules. Voyages des astronomes français à la recherche de la figure de la terre et de ses dimensions. Lille, 1890; LAFUENTE, Antonio. Una ciencia para el Estado: la expedición geodésica hispano-francesa al Virreinato del Perú, 1734-1743. Revista de Indias, v.43, n.172, p.549-629, 1983; e MERCIER, Roger. Les Français en Amérique du Sud au XVIIIe siècle: la mission de l'Académie des sciences (173545). Revue française d'histoire d'outre mer, v.56, n.205, p.327-374, 1969.

${ }^{6}$ Marqués de VALLEUMBROSO para LA CONDAMINE, Cuzco, 12 March 1742, British Library (BL), Add. MSS 20793, p.322-340. Os periódicos de Pablo Maroni foram mais tarde compilados e publicados como Noticias autenticas del famoso rio Marañon [1738]. Iquitos: IIAP-Ceta, 1988.

${ }^{7}$ RODRÍGUEZ CASTELO, Hernán. El Padre Samuel Fritz: Diario. Quito: Academia Ecuatoriana de la Lengua, 1997.

${ }^{8}$ Marqués de VALLEUMBROSO to LA CONDAMINE, p.325.

${ }^{9}$ Marqués de VALLEUMBROSO to LA CONDAMINE, p.331.

${ }^{10}$ MEEK, Ronald. Social science and the ignoble savage. Cambridge: Cambridge University Press, 1976.

${ }^{11}$ Sobre Magnin, ver MAGNIN, Jean. Description de la Province et des missions de Maynas au Royaume de Quito. In: HENKEL, Thomas (Org.). Chronique d'un chasseur des âmes: un jésuite suisse en Amazonie au XVIIIe siècle. Fribourg: Éd. de l'Hèbe, 1993; BAYLE, Constantin. Descubridores jesuitas del Amazonas. Revista de Indias, n.1, p.121-185, 1940.

${ }^{12}$ ARTUR, Jacques-François. Histoire des colonies françoises de la Guianne. v.2, p.557581. Bibliothèque Nationale (Paris), MS N. Acq. Fr. 2572. Reproduzido como "Pièce Justificative No. 1, Relation du D.r Artur.” In: FROIDEVAUX, Henri (Org.). Observations scientifiques de La Condamine pendant son séjour à Cayenne (1744). Paris: Imprimerie Nationale, 1898. p.23.

${ }^{13}$ ISAAC DE PINTO para LA CONDAMINE, s.d., BL, Egerton MSS 1745, fol. 181. 
${ }^{14}$ ISAAC DE PINTO para LA CONDAMINE, s.d., fol. 184.

${ }^{15}$ ISAAC DE PINTO para LA CONDAMINE, s.d., fol. 185.

${ }^{16}$ ISAAC DE PINTO para LA CONDAMINE, s.d., fol. 182v. O tema da degradação do Novo Mundo seria tomado por Buffon, De Pauw e outros, e levaria a uma disputa que engajou intelectuais dos dois lados do Atlântico, incluindo Thomas Jefferson e o jesuíta Francisco Xavier Clavigero. O clássico relato dessa "disputa do Novo Mundo" é de GERBI, Antonello. La disputa del Nuovo Mundo: storia di una polemica, 1750-1900. nuova ed. Milano: Adelphi, 2000. Para uma avaliação mais recente do tema, abrangendo um âmbito mais largo de fontes, ver CANIIZARES-ESGUERRA, Jorge. How to write the History of the New World. Stanford: Stanford University Press, 2001.

${ }^{17}$ ISAAC DE PINTO para LA CONDAMINE, s.d., fol. 184.

${ }^{18}$ Sobre a teoria do clima no século XVIII, ver GLACKEN, Clarence J. Traces on the Rhodian Shore: Nature and culture in Western thought from ancient times to the end of the eighteenth century. Berkeley: University of California Press, 1967. p.562; GERBI, 2000, p.55; KOLLER, Armin Hajman. The theory of environment: an outline of the history of the idea of milieu, and its present status. Menasha: George Banta Publishing, 1918; sobre Du Bos, ver LOMBARD, Alfred, L'abbé Du Bos: un initiateur de la pensée moderne, 16701742. Nouvelle éd. Geneva: Slatkine reprints, 1969.

${ }^{19}$ DU BOS, Abbé. Réflexions critiques sur la poësie \& sur la peinture, 3v. Nouvelle éd. Geneva; Paris: Slatkine reprints, 1982. v.2, p.287.

${ }^{20}$ ISAAC DE PINTO para LA CONDAMINE, s.d., fol. 182. Não se deve esquecer que eles também eram crioulos, até certo grau. Descendentes de uma das comunidades mais integradas em Amsterdã do século XVII, a dos judeus sefarditas de extração portuguesa, Isaac de Pinto e seu colega sefardita prontamente compreenderam os desafios e particularidades de viver como membros de uma cultura específica e agrupamento social baseado na reivindicação de uma linhagem de sangue.

${ }^{21}$ ISAAC DE PINTO para LA CONDAMINE, s.d., fol. 184.

${ }^{22}$ La Condamine rejeitaria mais tarde essa reivindicação: "Eu não acredito que ... as revoluções que certamente chegariam algum dia à América seriam causadas pelos nativos ( $n a-$ turels) do país, de acordo com as ideias que desenvolvi [durante minha viagem]" LA CONDAMINE para ISAAC DE PINTO, 17 Sept. 1746, BL, Egerton MSS 1745, fol. 187.

${ }^{23}$ ISAAC DE PINTO para LA CONDAMINE, s.d., fol. 185.

${ }^{24}$ Para uma discussão mais detalhada das críticas de Maldonado e Isaac de Pinto, ver SAFIER, 2008, cap. 3.

${ }^{25}$ HUMBOLDT, Alexander von. Relation historique du voyage aux régions equinoxiales $d u$ nouveau continent, fait en 1799, 1800, 1802, 1803, et 1804. Stuttgart: F. A. Brockhaus, 1970. v.2, p.484-485.

${ }^{26}$ Sobre o movimento de escravos fugitivos entre o Grão-Pará e Caiena nos séculos XVIII e XIX, ver ACEVEDO MARIN, Rosa Elizabeth; GOMES, Flávio. Reconfigurações colo- 
niais: tráfico de indígenas, fugidos e fronteiras no Grão-Pará e Guiana francesa (séculos XVII e XVIII). Revista de História, n.149, p.69-107, 2003.

${ }^{27}$ SAMPAIO, Francisco Xavier Ribeiro de. Diario da viagem, que em visita, e correição das povoações da Capitania de S. Jozé do Rio Negro, fez o Ouvidor, e Intendente Geral da mesma Francisco Xavier Ribeiro de Sampaio no anno 1774, e 1775. Lisboa: Academia das Sciencias, 1825. p.39.

${ }^{28}$ ROUSSEAU, Jean-Jacques. Discours sur l'origine et les fondements de l'inégalité parmi les hommes. Amsterdam: Marc Michel Rey, 1755.

Artigo recebido em fevereiro de 2009. Aprovado em março de 2009. 